H: $\mathrm{C}: 3.00: \mathrm{MN} \quad 65$

\title{
Determination of the Parameters
}

\author{
of
}

Nuclear States

,

Annual Report of AEC Contract AT(11-1) - 1663

Kansas State University, Manhattan, Kansas

\section{E. Mandeville, Principal Investigator}




\section{DISCLAIMER}

This report was prepared as an account of work sponsored by an agency of the United States Government. Neither the United States Government nor any agency Thereof, nor any of their employees, makes any warranty, express or implied, or assumes any legal liability or responsibility for the accuracy, completeness, or usefulness of any information, apparatus, product, or process disclosed, or represents that its use would not infringe privately owned rights. Reference herein to any specific commercial product, process, or service by trade name, trademark, manufacturer, or otherwise does not necessarily constitute or imply its endorsement, recommendation, or favoring by the United States Government or any agency thereof. The views and opinions of authors expressed herein do not necessarily state or reflect those of the United States Government or any agency thereof. 


\section{DISCLAIMER}

Portions of this document may be illegible in electronic image products. Images are produced from the best available original document. 


\section{Table of Contents}

I. Introductory Remarks 2

II. Decay of $\mathrm{Os}^{193}$ to $\mathrm{Ir}^{193}$

III. The Harder Garma Rays of Os ${ }^{191}, 16$

IV. Nuclear Energy States of $\mathrm{Eu}^{155} \quad 21$

V. Gamma Rays Emitted in Disintegration $\because 31$ of $\operatorname{Ir}^{192}$ and $\operatorname{Ir}^{194}$

VI. Additional Studies 32

VII. Personnel 34 


\section{Introductory Remarks}

The program concerning nuclear structure as revealed by radioactive decay has continued during the past year at Kansas State University. Sponsorship of this work by the AEC commenced on 1 November 1966 . During the preceding four years, simi lar measurements had been carried out under the auspices of the National Science Foundation. In consequence of this change of supporting federal agency, a period of overlap resulted in which certain previously unexpended funds of the National Science Foundation were used to support the work of this report concurrently with those monies which became available from the AEC on I November 1966.

Since the time of the previous annual report (Annual Report of the work of NSF GP-4945, issued in August, 1966), the following publications have appeared, resulting from this program.

1. "Some Nuclear States of Rh"103", V. R. Potnis, E. B. Nieschmidt, C. E. Mandeville, L. D. Ellsworth, and G. P. Agin, Phys. Rev. $146,883(1966)$.

2. "Radioactive Decay of Os 193", G. P. Agin, G. E. Clark, C. E. Mandeville, and V. R. Potnis, Bull. Am. Phys. Soc. Series II, 12,37 (1967).

3. "Radioactive Decay of Ir 192 and Ir ${ }^{194 ",}$ T. J. Palaska, V. R. Potnis, and C. E. Mandeville, Bull. Am. Phys. Soc. Series II, 12, 37 (1967). 
4. "Decay of Sm ${ }^{155 ", ~ V . ~ R . ~ P o t n i s, ~ G . ~ P . ~ A g i n, ~ a n d ~ C . ~ E . ~ M a n d e v i l l e, ~}$ Bull. Am. Phys. Soc. Series II, 12, 579 (1967).

5. "187-keV Transition in Ir 191 ", G. P. Agin, G. E. Clark, C. E. Mandeville, and V. R. Potnis, Bull. Am. Phys. Soc. Series II, 12,579 (1967).

6. "Gamma Rays Emitted in Disintegration of Ir 192 and Ir 194", T. J. Palaska, V. R. Potnis, and C. E. Mandeville, Nucl. Phys. A95, 673 (1967). 
II. Decay of Os $^{193}$ to $\underline{\operatorname{Ir}}^{193}$. 


\section{Abstract}

The energies and relative intensities of the gamma rays of 0 s $^{193}$ $\left(T_{f}\right.$ - 32h) have been measured with a $\mathrm{Ge}(L i)$ detector. Gamma-gamma colncidences and beta-gamma coincidences were studied to obtain energies of nuclear states in ir ${ }^{193}$. In all, twenty-four detected gamma transitions have been ordered between eleven nuclear energy states. The energies of these transitions are 73, 98, 107, 139, 180, 219, 252, 281, 289, 299, 322, 362, 379, $388,420,438,461,486,512,533,559,574,713$, and $874 \mathrm{keV}$, establishing excited energy states at $73,139,180,362,438,461,559,680,713$, and 874 keV in the nucleus of Ir ${ }^{193}$. Gamma rays corresponding to transition energies of 618,780 , and $830 \mathrm{keV}$ were also observed, but these transittons could not be suitably incorporated into the disintegration scheme. 


\section{Introduction}

The nuclear energy states of Ir ${ }^{193}$, as indicated by beta decay of 0 s $^{193}$. have been the subject of a number of relatively recent investigations. 1-5 In the course of the earlier studies ${ }^{1-4}$, such instruments as lens spectrometers, scintillation counters, and scintillation counters in coincidence were employed to determine the energies and relative intensities of the beta rays and gamma rays emitted in decay of the radionuclefde. The most recent investigation 5 involved the use of $\mathrm{Ge}(\mathrm{LI})$ detectors and such detectors coincident with scintillation counters.

The measurements of energies of gamma rays presently reported were carried out with utilization of a Ge(Li) detector (depletion layer thickness $4.2 \mathrm{~mm}$ ) and of the $\mathrm{Ge}(L I)$, detector coincident with a scintillation counter of $\mathrm{NaI}(T I)$. Beta ray spectra were measured with use of an anthracene counter which was in coincidence with the $G e(L 1)$ detectór. To produce $0 s^{193}\left(T_{t}=32 \mathrm{~h}\right)$. isotopically concentrated $0 s^{192}$, enrichment 98.7 percent, was irradiated for an exposure time of $0.5 \mathrm{~h}$ on six successive occasions in the Kansas State University Triga Mark II Reactor.

II. Spectra of Single Counts

As observed in the $\mathrm{Ge}(\mathrm{LI})$ detector, the garma rays of $0 \mathrm{~s}^{193}$ are shown in fig. I to a maximum quantum energy of $139 \mathrm{keV}$. The similarly detected spectrum of the harder gamma rays is shown in Fig. 2. From the areas under the full energy peaks, after appropriate corrections for detection efficiencies as a function of energy, preabsorption, and full energy peak to total ratios, the relative intensities of the gamma rays of $0 s^{193}$ were determined. The energies and relative intensities of the gamma rays so obtained are compared with the results of some of the earlier investigations in Table I. 
In estimating the intensity of the 73-keV gamma ray, the presence of the $K_{B} \times$ rays of iridium was taken into account. The intensity of the $K_{B}$ line was calculated from the measured intensity of the $k_{\alpha}$ line and known relative intensities of $K \times$ ray components. 6 The decay of the fuil energy peaks of all the quanta reported in Table I was followed over a time of three half periods to verify the isotopic assignment. It will be noted that several of the previously reported ${ }^{1-3}$ ganma rays of $0 s^{193}$ were not detected. However, eleven gamma rays, until the present unreported, were found.

\section{Gamma-gamma Coincidence Experiments}

The coincidence circuitry of the gamma-gamma coincidence experiments is shown in Fig. 3. The detectors were respectively a crystal of $\mathrm{NaI}(\mathrm{TI})$ (d. $2.54 \mathrm{~cm}, h .3 .81 \mathrm{~cm}$ ) and the $\mathrm{Ge}(L i)$ detector of depletion layer thickness $4.2 \mathrm{~mm}$. The schematic diagram of Fig. 3 shows how both true-plus-chance and chance coincidences alone are recorded. Pulses in the Ge(Li) detector which are coincident with any pulse in the scintillation counter are recorded in 1024 channels along the axis of abscissas of a multiparameter analyzer. Simflariy, pulses in the scintillation counter which are coincident with any pulse in the Ge(LI) detector are recorded in 512 channels along the axis of ordinates of the same analyzer. In an additional 512 channels along the axis of ordinates of the same analyzer are recorded pulses in the scintillation counter which are only in accidental coincidence with pulses recorded in the Ge(LI) detector. This sorting procedure for separation of true-plus-chance coincidences from accidental coincidences alone, is implemented by a steering circuit. Pairs of channel numbers (address pairs) corresponding to both the accidental coincidences and the true-plus-chance coincidences are stored in the buffer memory and subsequently deposited upon magnetic tape. Thus, in one 
extended period of data acquisition, every detectable true-plus-chance coincidence can be recorded simultaneously with observation of all detectable chance coincidences. The coincidence data on the magnetic tape can be displayed upon the multiparameter analyzer at any time following the direct observations. Channel widths for selecting "gate pulses" with which to obtain these successive passive displays are determined by the spectrum sorter. In the case of the actual measurements here being described, four, sorting channels at a time were arbitrarily set at chosen intervals of energy along the scintillation counter spectrum so as to display each of the entire coincident spectra recorded in the Ge(LI) detector.

The coincident counters were placed at an angle of 140 degrees with each other, and absorbers of lead, cadml um, copper, and aluminum were introduced between them to reduce backscattering effects.

Gamma rays coincident with the $K_{\alpha} \times$ rays of iridium are shown in Fig. 4. The particular features of this curve are that the presence of a 98-keV gamma ray is shown more clearly, and that the 461-keV gamma ray is shown to be preceded by partially converted quanta. Heretofore, ${ }^{1-3}$ the level from which this gamma ray is emitted had been thought to be directly fed only by beta rays.

In fig. 5 are shown gamma rays coincident with gate positions centered at 107, 139, and $180 \mathrm{keV}$. The spectrum of single counts in the gating crystal of $\mathrm{NaI}(\mathrm{TI})$ is shown as an insert in the figure. Gamma ray full energy peaks which are coincident with full energy peaks in the gate positions are indicated as to energies in $\mathrm{keV}$ without parenthetical marks. Full energy peaks distinguished in energy by parenthetical marks are those which arise from coincidences with Compton recolis of harder quanta which fall in the gating region, or from inclusion of parts of neighboring full energy peaks in the gate. 
Five gate positions, at 219,251,281, 289, and $299 \mathrm{keV}$, were employed to obtain the coincidence data of Fig. 6. Of these, only the 299-keV gama ray is non-coincident with the 73-keV gamma ray which is emitted from the first excited state ${ }^{1,4}$ of $\mathrm{Ir}^{193}$. The three most energetic gamma rays providing this group of gate pulses are seen to be non-coincident with one another. Parenthetical marks are to be interpreted as in Fig. 5.

Four additional gate positions at $322,388,420$, and $461 \mathrm{keV}$ were utilized to provide the coincidence data of Fig. 7. The curves indicate that only the 388 and $420-\mathrm{keV}$ gamma rays are coincident with the 73-keV gamma ray. Only the 322 and $420-\mathrm{keV}$ gamma rays are coincident with the 139-keV gamma ray which is emitted in de-excitation of the second excited state $^{1,4}$ of Ir193. These data also show the $461-\mathrm{keV}$ gamma ray, emitted in a transition to the ground state ${ }^{1-4}$, to be coincident with gamma rays at 98,219 , and $252 \mathrm{keV}$.

In Figs. 5-7, the intensity of the peak appearing at the $K_{\beta} x$-ray energy is seen to fluctuate in intensity relative to the $K_{a}$ line, showing it to be a mixture of $K_{\beta}$ radiation and 73-keV gamma rays.

\section{Beta-gamma Coincidence Experiments}

Taking gating pulses from the $\mathrm{Ge}(L i)$ detector, beta-gamma coincidences were measured. The beta rays were detected in an anthracene scintillation counter. The axes of the cylindrically shaped counters were at an angle of 140 degrees with each other, and the Ge(LI) detector was shielded from beta rays by a plastic absorber. Fermi plots of beta spectra coincident with certain of the gamma rays are shown in Figs. 8 and 9 . Because of poor resolution of the anthracene counter and poor statistical accuracy attainable, these data are interpreted to indicate an uncertainty of about $30 \mathrm{keV}$ in 
determination of the end points of the respective beta spectra. For example, in Fig. 8, gamma ray gate pulses at 107 and $180 \mathrm{keV}$ are considered to be coincident with the same beta spectrum. That the 107 and $180-k e V$ gamma rays are emitted from the same level is consistent with the fact that these quanta are non-coincident with each other.

\section{The disintegration scheme of os $^{193}$}

Coulomb excitation experiments 7,8 have established energy states in Ir 193 at 73,140 , and $357 \mathrm{keV}$. The 140 and $357-\mathrm{keV}$ states have been interpreted 7,8 as having spin-parity assignments of $5 / 2^{+}$and $7 / 2^{+}$, forming a rotational band with the ground state of Ir ${ }^{193}$, which has a measured ${ }^{9} \operatorname{spin}$ of $3 / 2$, and a positive parity if principles of the nuclear shell model are invoked. The measurement of the $L_{1}: L_{2}$ ratiolo suggests the $73-\mathrm{keV}$ gamma ray to be emitted in an $M 1+E 2$ transition. This result accords with shell model predictions that the spin-parity assignment of the $73-\mathrm{keV}$ level should be $1 / 2^{+}$.

The presence of the three previously discussed energy states is confirmed by the measurements of this paper. Moreover, the beta-gamma and gamma-gamma coincidence experiments and precise energy measurements of the present provide evidence for the remaining energy states of the residual nucleus shown in Fig. 10 where $Q_{B \text { - }}$ is taken to be $1132 \mathrm{keV} .11$ The spin-parity assignment of the $180 \mathrm{keV}$ state has been taken $1 / 2^{+}, 3 / 2^{+}$in analogy with the proposed 12 spin-parity values of the corresponding level at $179 \mathrm{keV}$ in Ir 191 which is excited in the orbital electron capture decay of $\mathrm{Pt}^{191}$. For comparison, the energy states of Ir 193 as obtained by a number of investigators or groups. of investigators are given in Fig. 11. Not shown in this figure are energy states at 660,713 , and $874 \mathrm{keV}$ which have been specifically mentioned in the most recent report. 5 
Ideally, it would be desirable to calculate'log $\mathrm{ft}$ for each of the beta spectra associated with the decay of 0s 193. However, the internal conversion coefficients of at least thirteen of the gamma ray transitions of Fig. 10 are as yet unknown, making it impossible to compute the percent of beta rays in each spectrum from the relative intensities of the unconverted quanta given in Table I.

Some of the low lying energy states of $\operatorname{Ir}^{193}$ can be explained by the nuclear model in which core plus particle are weakly coupled.13-15 When a single proton of orbital $d_{3 / 2}$ is added to the nuclear core of $0 s^{192}$ in its first excited state $(2+)$, the spins and parities of the first four excited states of Ir 193 can be predicted, if the spin-parity assignment of the 180keV level is indeed taken to be $3 / 2^{+}$.

In Fig. 2 and Table I of this paper are listed gamma rays at 618, 780, and $830 \mathrm{keV}$. Though these quanta exhibited the proper decay time of $0 \mathrm{~s}^{193}$. they do not appear to be coincident with any other gamma rays of $0 s^{193}$. Moreover, these garma rays do not correspond in energy to any available positions in the disintegration scheme of Fig. 10 .

The transition denoted by the broken line in Fig. 10, originating at the level of excitation energy $362 \mathrm{keV}$, has been located according to energy considerations. The gamma ray itself has been recently detected 16 . If indeed the 182-keV gamma ray has been correctly placed in the disintegration scheme of Fig. 10, parenthetical marks should be removed from 180, Fig. 5 ,

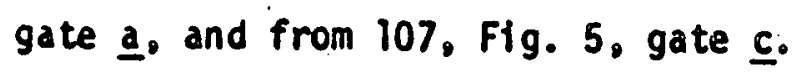


Table I. Energies and relative intensities of the gamma rays of oslys, emitted in de-excitation of $\operatorname{Ir}^{193}$. Reference numbers are those of the text. Energies are in kev. Relative intensities are within parenthetical marks.

\begin{tabular}{|c|c|c|c|c|c|c|c|}
\hline \multicolumn{2}{|c|}{ Ref. 1} & \multicolumn{2}{|c|}{ Ref. 2} & \multicolumn{2}{|c|}{ Ref. 3} & \multicolumn{2}{|c|}{ Present results } \\
\hline 73 & & 73 & & 73 & $(434)$ & 73. & $(45 \pm 2)$ \\
\hline- & & - & & - & & 98 & $(0.7 \pm 0.1)$ \\
\hline 106 & & 106.8 & $(2.54)$ & 106 & $(66.6)$ & 107 & $(10.8 \pm 0.5)$ \\
\hline 138 & & .139 .3 & $(78.6)$ & 139 & $(333)$ & 139 & $(82 \pm 1)$ \\
\hline$\ldots$ & & 180 & $(2.54)$ & 180 & $(10)$ & 180 & $(7.1 \pm 0.1)$ \\
\hline$\ldots$ & & 196 & $(1.78)$ & - & & $\cdots$ & \\
\hline$\ldots$ & & -- & & 223 & $(16.7)$ & 219 & $(5.8 \pm 0.1)$ \\
\hline 234 & & -- & & 235 & $(16.7)$ & - & \\
\hline- & & 243 & $(2.54)$ & -- & & - & \\
\hline- & & 248.5 & $(5.58)$ & -- & & -- & \\
\hline 252 & (1) & 251.4 & $(6.85)$ & 251 & $(16.7)$ & 252 & $(4.6 \pm 0.1)$ \\
\hline-- & $\therefore$ & 278 & $(13.5)$ & -- & & $=$ & \\
\hline & (15) & 281 & $(33.0)$ & 280 & $(66.6)$ & 281 & $(35.6 \pm 0.4)$ \\
\hline- & - & 288.5 & $(5.58)$ & - & & 289 & $(4.2 \pm 0.2)$ \\
\hline- & & 299.4 & $(7.36)$ & - & & 299 & $(2.4 \pm 0.4)$ \\
\hline-- & & - & & 308 & $(10)$ & - & \\
\hline-- & & 314 & $(5.84)$ & -- & & - & \\
\hline 320 & (21) & 321.8 & $(34.5)$ & 321 & $(43.4)$ & 322 & $(27.0 \pm 0.7)$ \\
\hline 356 & $(6)$ & 362 & $(11.4)$ & 362 & $(10)$ & 362 & $(6.9 \pm 0.1)$ \\
\hline- & & - & & -- & & 379 & $(1.6 \pm 0.2)$ \\
\hline & (32) & 387.8 & $(35.6)$ & 387 & $(33.3)$ & 388 & $(23.9 \pm 0.4)$ \\
\hline- & & 419 & & - & & 420 & $(5.5 \pm 0.4)$ \\
\hline$=$ & & - & & - & & 438 & $(2.1 \pm 0.2)$ \\
\hline 458 & $(100)$ & 460.4 & $(100)$ & 460 & $(100)$ & 467 & $(100)$ \\
\hline$\ldots$ & & 485.7 & $(6.35)$ & -- & & 486 & $(4.6 \pm 0.1)$ \\
\hline
\end{tabular}


Table I - Continued

\begin{tabular}{|c|c|c|c|c|c|c|c|}
\hline$\cdots$ & & - & & -- & & 512 & $(0.31 \pm 0.04)$ \\
\hline- & & - & & $\cdots$ & & 533 & $(1.9 \pm 0.1)$ \\
\hline 558 & (45) & 558.5 & (53.3) & 558 & $(40)$ & 559 & $(48.2 \pm 0.2)$ \\
\hline- & $\dot{1}$ & $\ldots$ & & $=$ & . & 574 & $(0.4 \pm 0.1)$ \\
\hline$=$ & & $\cdots$ & & $=$ & & 618 & $(1.2 \pm 0.1)$ \\
\hline- & & - & & - & & 713 & $(0.42 \pm 0.03)$ \\
\hline$\therefore$ & $\because$ & - & & - & & 780 & $(1.9 \pm 0.1)$ \\
\hline -. & & $\ldots$ & & - & & 830 & $(0.62 \pm 0.06)$ \\
\hline$\ldots$ & & $\cdots$ & & -- & & 874 & $(0.57 \pm 0.06)$ \\
\hline
\end{tabular}




\section{References}

1. V. S. Dubey, S. S. Malik, C. E. Mandevtlle, and A. Mukerj1, Phys. Rev. 111.920 (1958).

2. S. V. Nablo, M. W. Johns, A. Artna, and R. H. Goodmạn, Can. J. Phys. 36, 1409 (1958). This paper contains references to many earlier investigations of the decay of Os ${ }^{193}$.

3. L. Feuvrais, Ann. Phys. 5, 181 (1960).

4. E. E. Habib-Thesis, McMasters University, Hamilton, Ontario, Canada (1961).

5. F. C. Perry and E. S. Murphy, Jr., Bull. Am. Phys. Soc. II, 11, 408 (1966).

6. Nuclear Spectroscopy Tables, A. H. Wapstra, G. J. Nijgh, and R. van Lieshout (North-Holland Publishing Co., Amsterdam, p. 81. 1959).

7. E. M. Bernstein and H. W. Lewis, Phys. Rev. 105, 1524 (1957).

8. F. K. McGowan and P. H. Stelson, Phys. Rev. 109, 901 (1958).

9. W. von Siemens, Ann. Physik 13, 136 (1953).'

10. J. M. Cork, J. M. LeBlanc, W. H. Nester, D. W. Martín, and M. K. Brice, Phys. Rev. 90, 444 (1953).

11. Nuclear Data Sheets, compiled by $K$. Way et. al. (Printing and Publishing Office, National Academy of Sciences--National Research Councti, Washington, D. C.).

12. B. Harmatz, T. H. Handley, and J. W. Minelich, Phys. Rev. 128, 1186 (1962).

13. R. D. Lawson and J. L. Uretsky, Phys. Rev. 108, 1300 (1957).

14. A. de-Shalit, Phys. Rev. 122, 1530 (1961).

15. P. M. Rinard (private communication).

16. P. Alexander and H. Ryde, Bull. Am. Phys. Soc: II, 12, 597 (1967). 


\section{Captions}

Fig. 1 - Spectrum of softer gamma rays of $0 s^{193}$. Energies in keV. These data and those of four similar accumulations were combined to obtain the relative intensities of gamma rays shown in Table $\mathrm{I}$.

Fig. 2 - Spectrum of the harder gamma rays of $0 s^{193}$. Energies in keV. These data and those of four similar accumulations were combined to obtain the relative intensities of gamma rays shown in Table I.

Fig. 3 - Block diagram of electronic circuitry for obtaining betagamma and gamma-gamma coincidences.

Fig. 4 - Spectrum in Ge(Li) of gamma rays of 0 s $^{193}$ which are coinctdent with the $K a \times$ rays of $I^{193}$. Energies in keV. Pulses of the coincidence gate were taken from the low energy region of the Ka peak in such manner as to exclude any contribution to the gate of pulses in the $K_{\beta}+73$ peak.

Fig. 5 - Spectra in Ge(L1) of gamma rays of 0 s $^{193}$ which are coincident with quanta at 107, 139, and $180 \mathrm{keV}$. Insert at upper right shows gate positions in $\mathrm{NaI}(\mathrm{TI})$ counter spectrum. Energies are in keV. Significance of parenthetical marks is discussed in text .

Fig. 6 - Spectra in $\mathrm{Ge}(L i)$ of gamma rays of $0 \mathrm{~s}^{193}$ coincident with quanta at $219,251,281,289$, and $299 \mathrm{keV}$. Insert at upper left shows gate positions in $\mathrm{NaI}(\mathrm{TI})$ counter spectrum. Energies are in keV.' Significance of parenthetical marks is discussed in text.

Fig. 7 - Spectra in Ge(Li) of gamma rays of 0 s $^{193}$ coincident with quanta at 322, 388, 420, and $461 \mathrm{keV}$. Insert at top center shows gate positions in NaI(TI) counter spectrum. Energies are in keV. Significance of parenthetical marks is discussed in text. 
Fig. 8 - Fermi plots of beta-gamma coincidences in decay of $05^{193}$. All energies in keV. Gate positions were at 107, 139, 180, and 362 keV in the Ge(Li) spectrum. Beta spectra were recorded in an anthracene scintillation counter.

Fig. 9 - Fermi plots of beta-gamma coincidences in decay of 0 ș $^{193}$. All energies in keV. Gate positions were at $322,388,420,461$, 486 and $559 \mathrm{keV}$ in the $\mathrm{Ge}(L 1)$ spectrum. Beta spectra were recorded in an anthracene scintillation counter.

Fig. 10 -Oisintegration scheme of $05^{193}$. All energies in keV. Beta ray end point of the ground state transition is taken from Ref. 11 . Data concerning the proposed $182-k e V$ transition are contained in Ref. 16 of the text.

Fig. 11 . Energy states of Ir ${ }^{193}$ as proposed by some prior investigators and presently. Energies in keV. 


\section{$O_{s}{ }^{193}$}

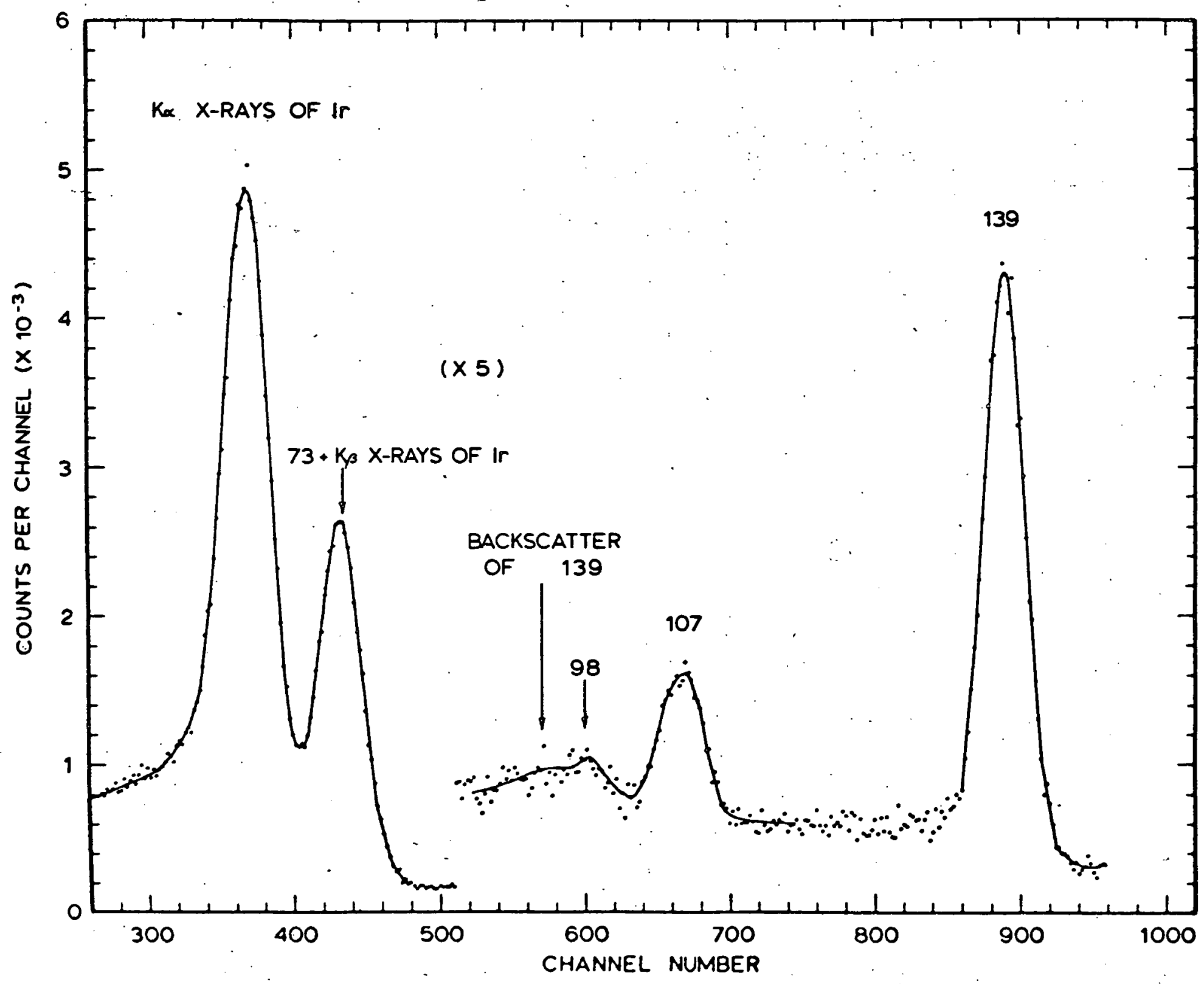

Fig. 1 


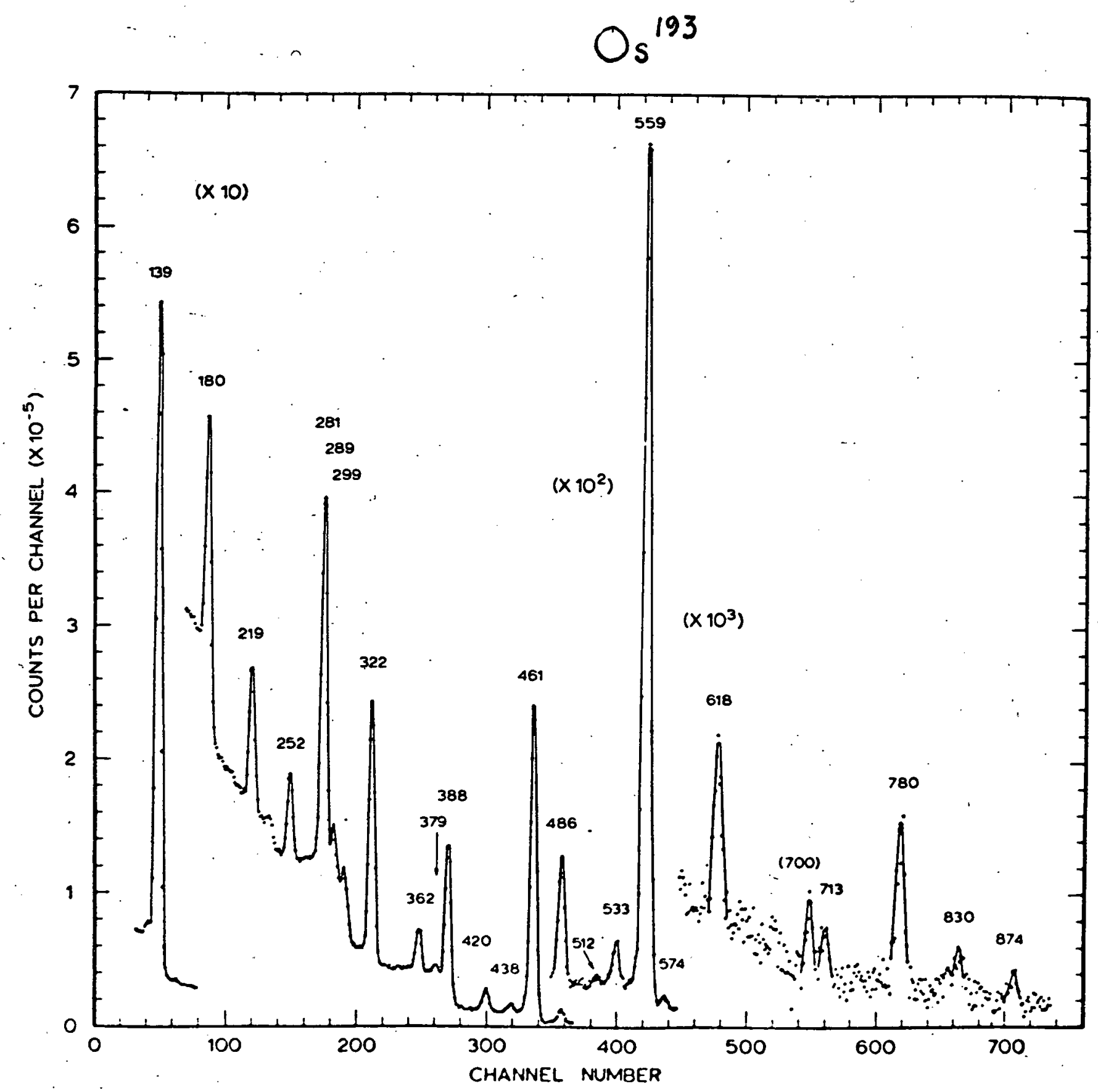

Fig. 2 


\section{$O s^{193} \stackrel{\beta^{-}}{\longrightarrow} I_{r}{ }^{193}$}
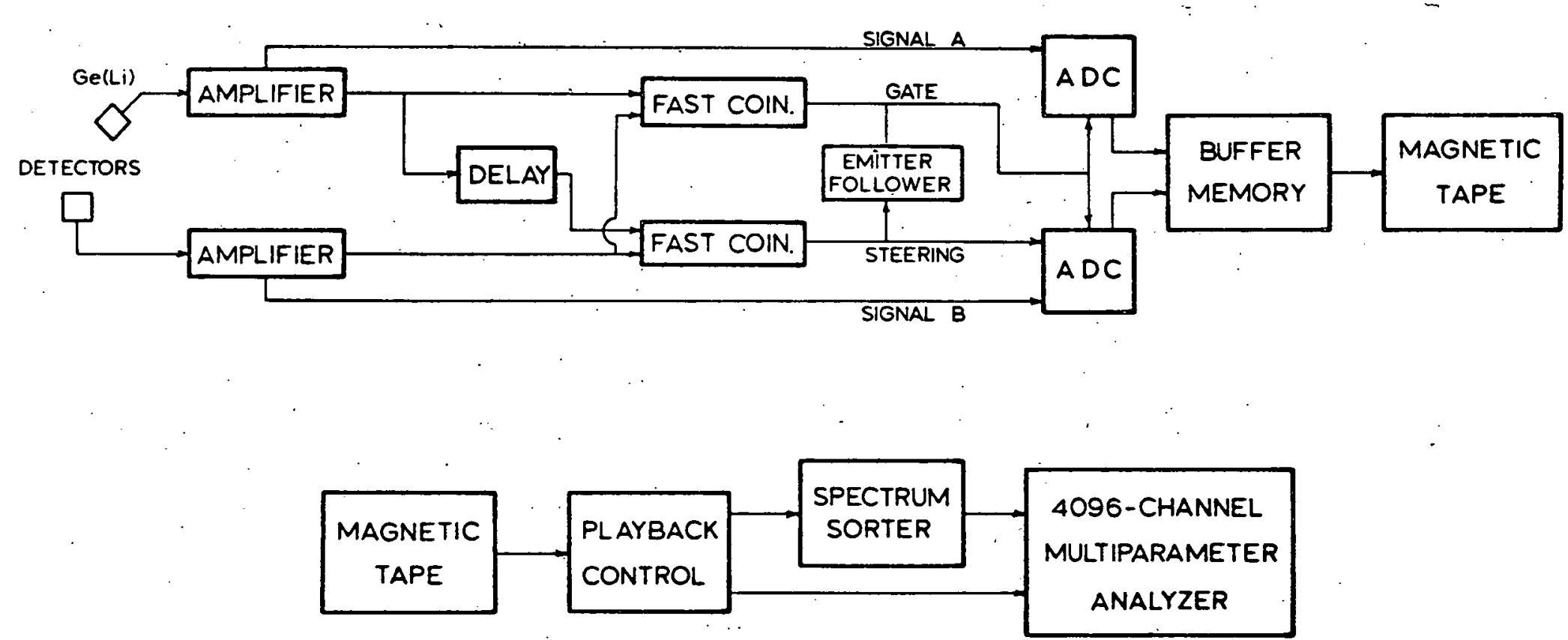

Fig. 3 


\section{$O s^{193}$}

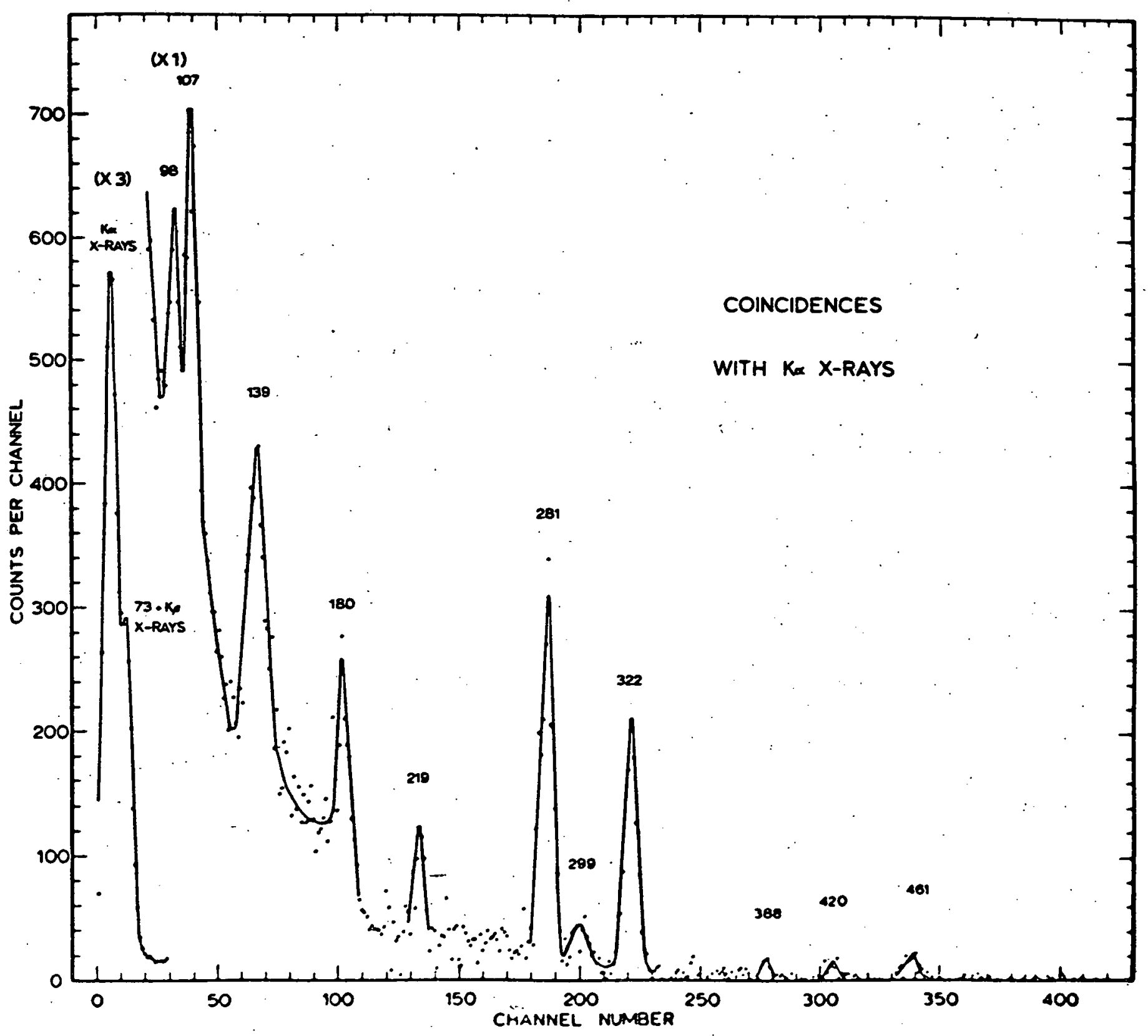

Fig. 4 
$O s^{193}$

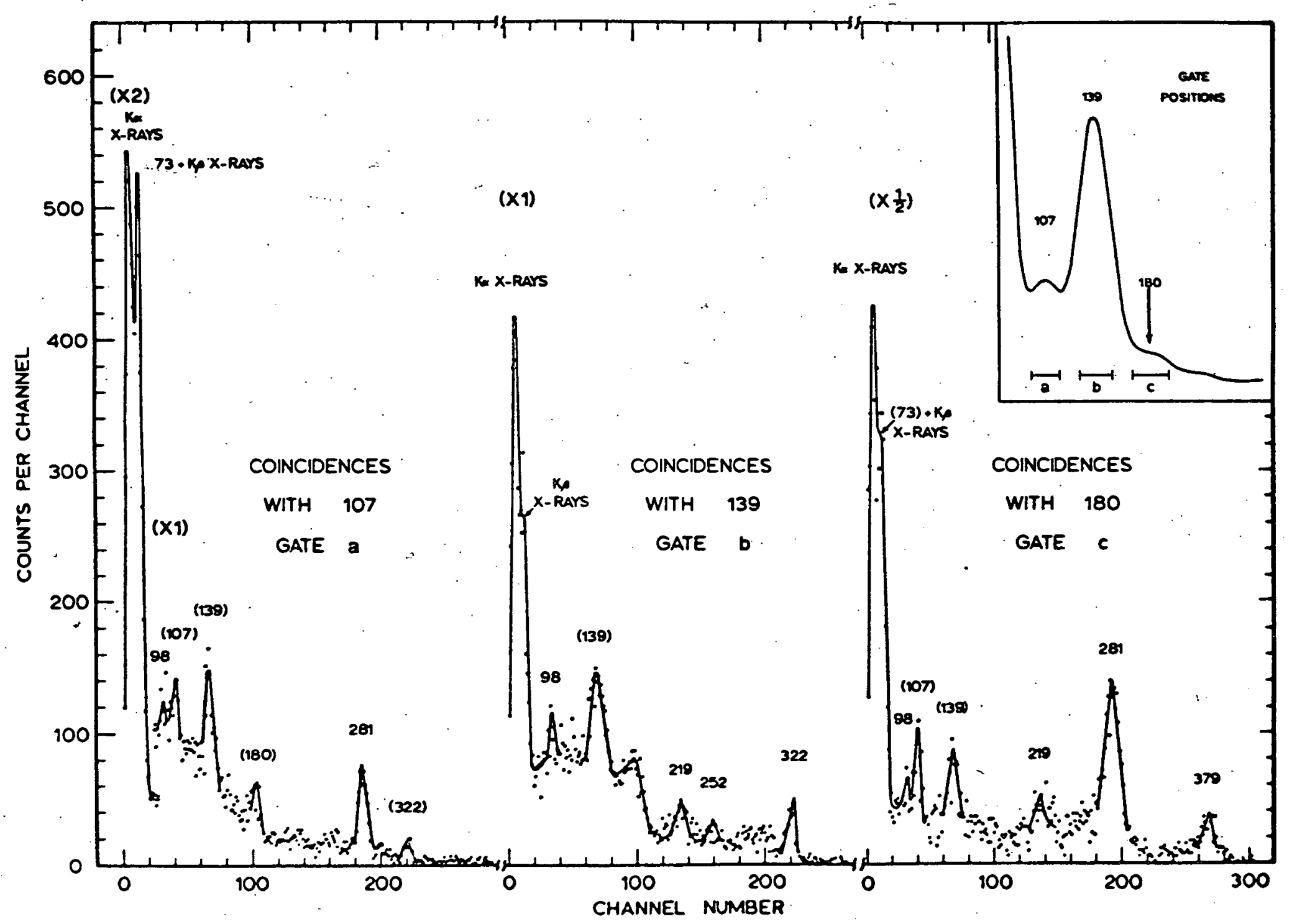

Fig. 5 
$\mathrm{Os}^{193}$

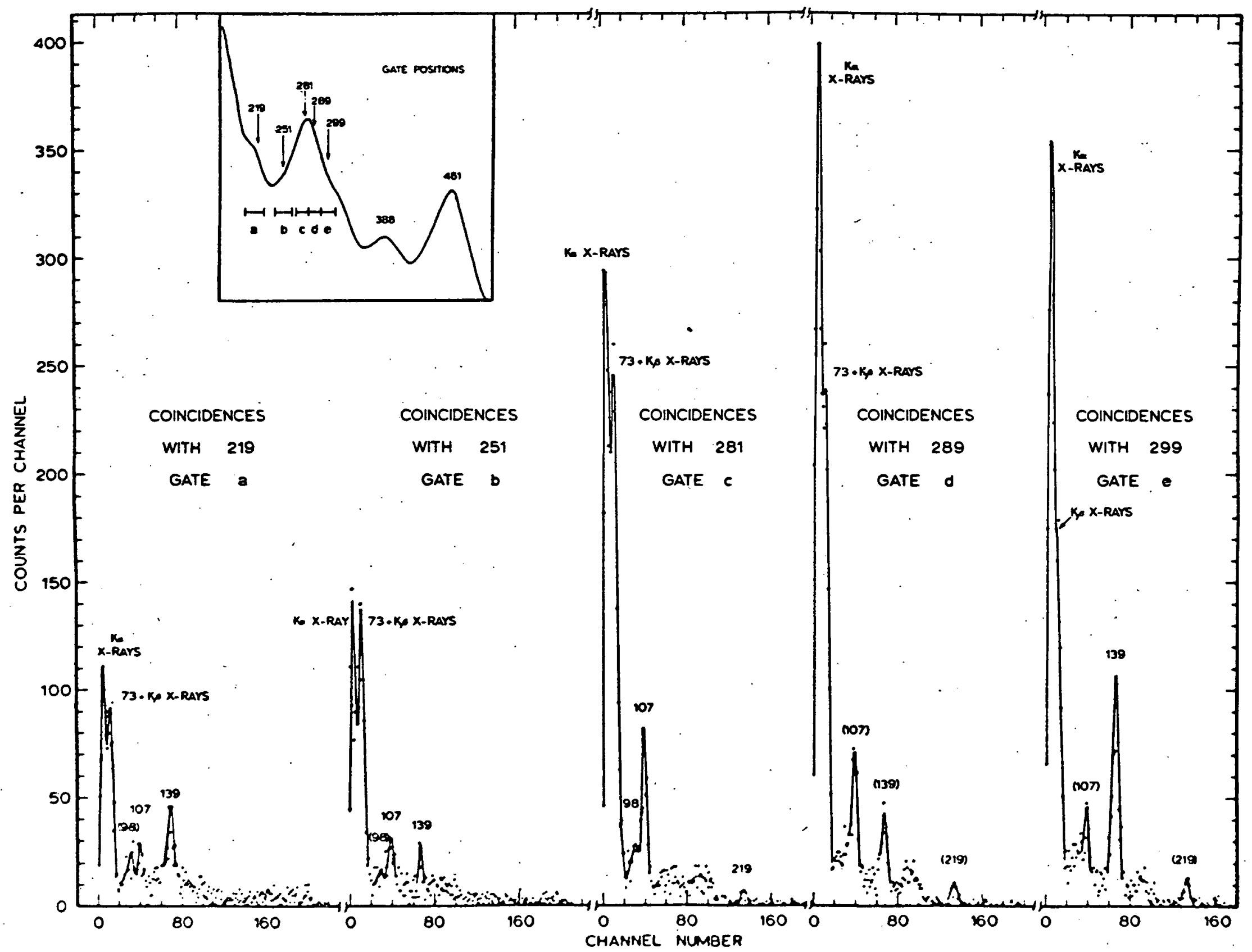

Fig. 6 


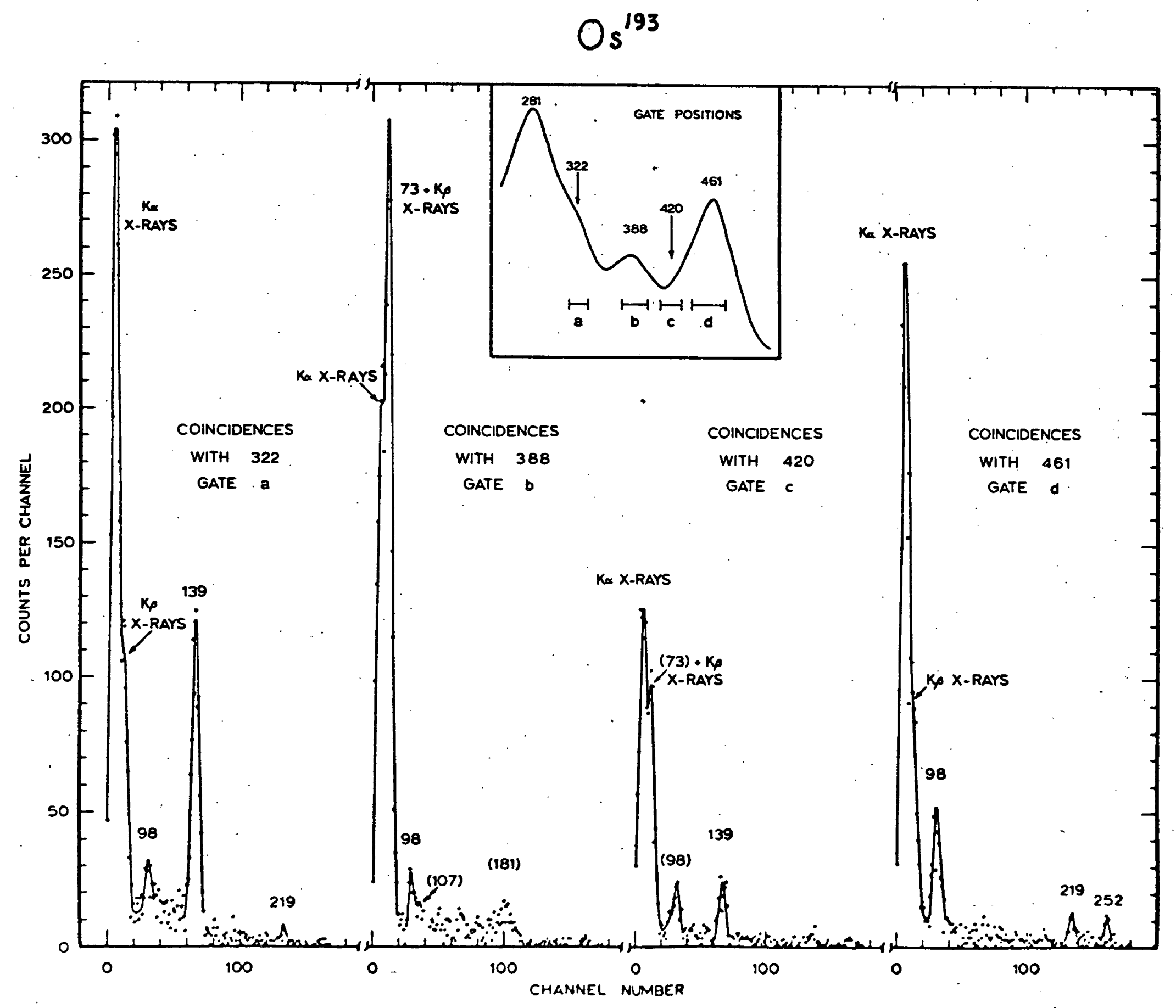

$F_{i b} \cdot ?$ 


\section{$\mathrm{Os}_{s}{ }^{193} \bar{\beta} \rightarrow I^{193}$}
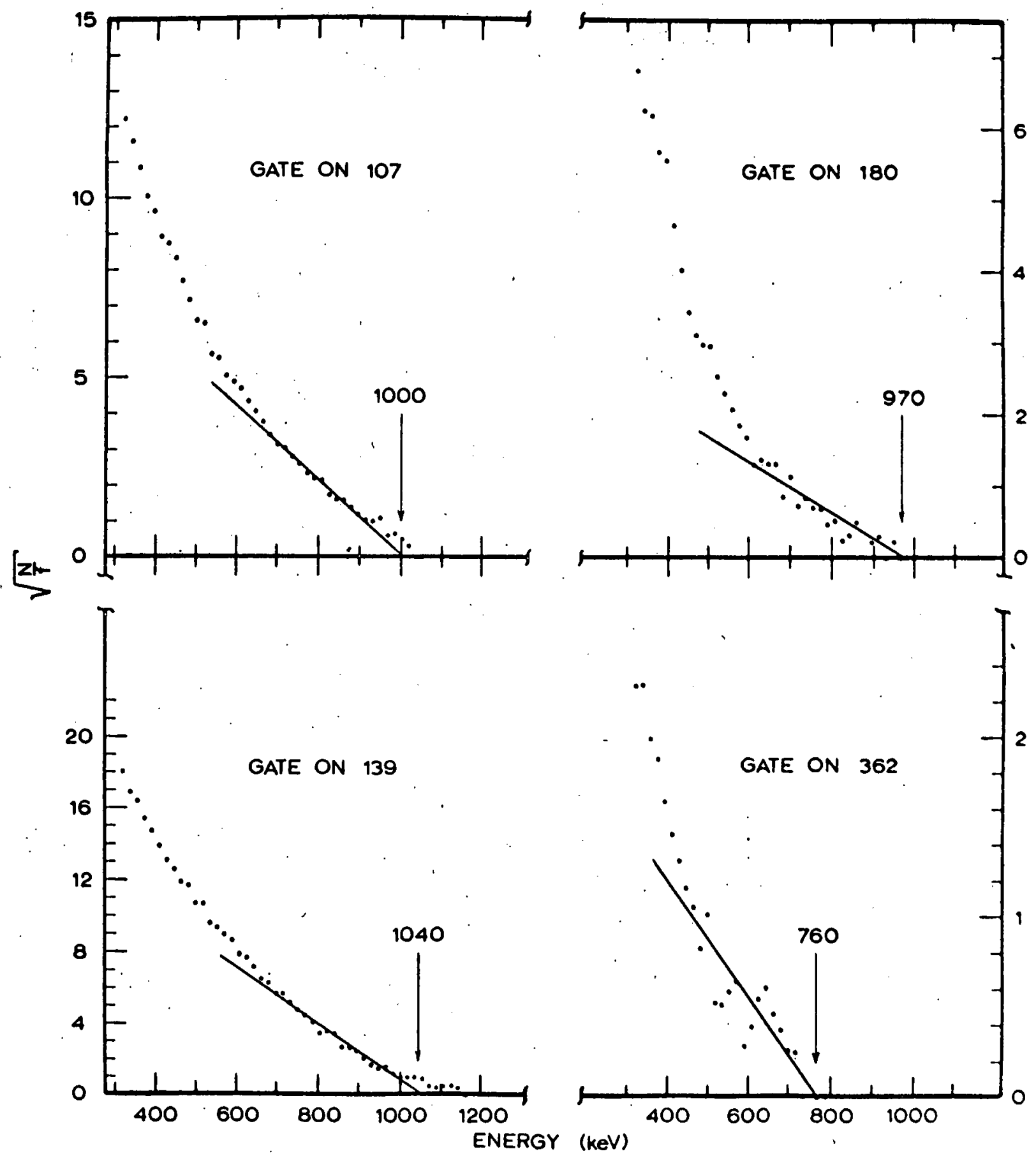

Fig. 8 


\section{$\mathrm{O}_{s}^{193} \stackrel{\beta^{-}}{\longrightarrow} I_{\alpha}{ }^{193}$}

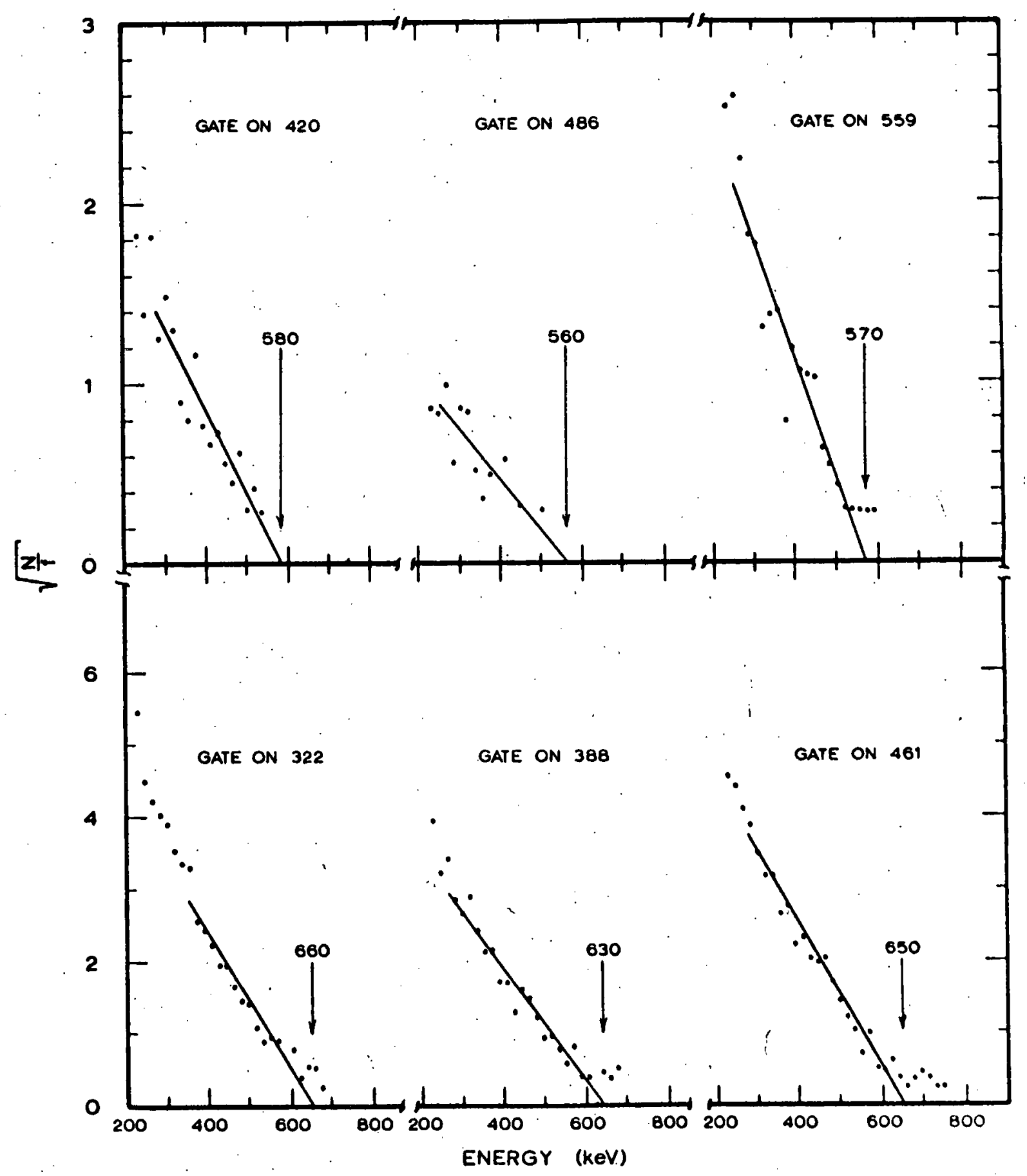

Fig. 9 


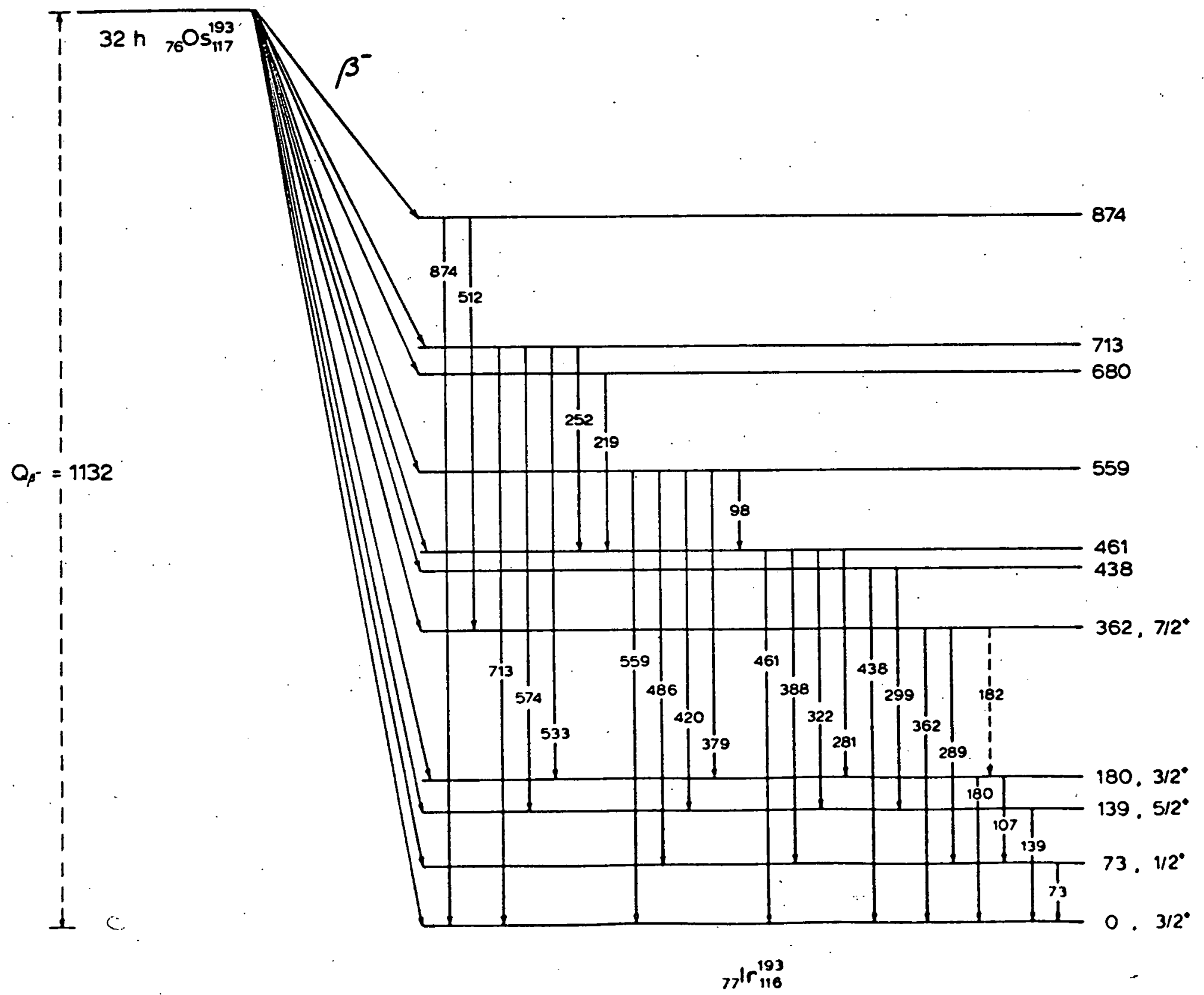

Fig. 10 
$\operatorname{Ir}^{193}$

713

680

613

558

559

$5585 / 2^{4}$

559

$4601 / 2^{+}$

461

460

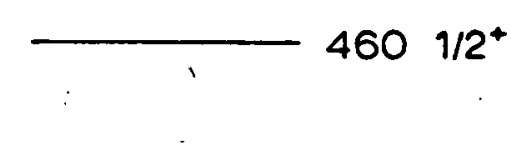

362

$362,712^{*}$

356

362, $\left(7 / 2^{+}\right)$
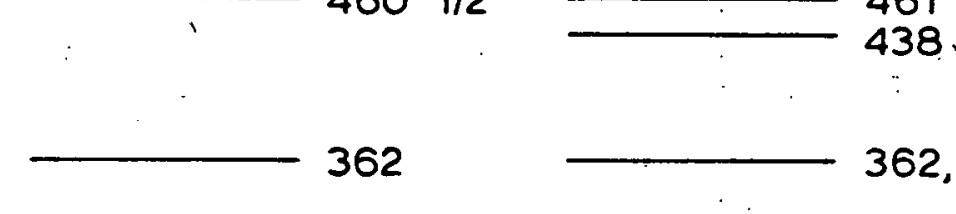

315

281

247

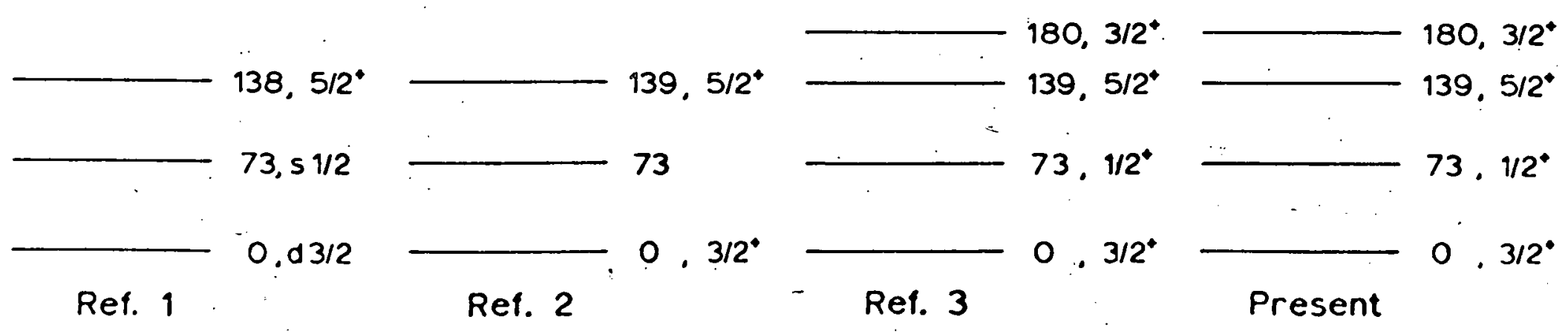

Fig. $11 \quad O_{s}^{193} \stackrel{\beta}{\rightarrow} I_{\pi}^{193}$ 
III. The Harder Gamma Rays of $0 \mathrm{~s}^{191}$. 


\section{Abstract}

${ }^{191}$ Os was produced by slow neutron capture in ${ }^{190}$ Os. A gamma ray at $187 \mathrm{keV}$ was emitted from the irradiated target material, but its intensity was found to decay with a haif life different from that of $191_{\text {Os. }}$. 
A gamma ray of energy $185.8 \mathrm{keV}$ has been reported to be emitted in the beta decay of the 15 day 1910 s, and correspondingly, a nuclear energy state has been proposed at $186 \mathrm{keV}$ in ${ }^{191} \mathrm{Ir}$, the residual nucleus [1]. A subsequent investigation [2] has revealed no evidence for the presence of this gamma ray.. The accepted disintegration schemes [3] of the isomers of 1910 s are given in fig. 1 , in which the proposed transition, energy state, and related beta transition are indicated by broken lines.

To produce ${ }^{191} 0 \mathrm{~s}$, five milligrams of isotopically concentrated 1900 s, enrichment 95.5 percent, were irradiated for a time of two hours in the KSU Triga Mark II reactor. The quantum radiations of the 15 day 1910 sere measured as to energies and relative intensities in a $\mathrm{Ge}(\mathrm{Li})$ detector of depletion layer thickness $4.2 \mathrm{~mm}$. The resolution in energy was $4 \mathrm{keV}$.

The spectrum of the harder gamma rays of ${ }^{191} 0$ s is shown in fig. 1. Quanta at 129 and $187 \mathrm{keV}$ were observed, but when the half periods of their. full energy peaks were measured as also indicated in fig. 1 , the $187 \mathrm{keV}$ peak was found to have a half life of $9.9 \pm 0.5$ days. Thus, the $187 \mathrm{keV}$ gamma ray cannot be associated with the decay of $191_{0 \mathrm{O}}$, but rather with the induced activity of an impurity. For this reason, the broken lines of fig. I should not be considered real parts of the disintegration scheme. Relative to the intensity of the 129-keV gamma ray, that of the 187-keV gamma ray has been reported [1] to be. 0.38 . The 187-keV gamma ray of fig. I of this report has been calculated to have an intensity of 0.040 relative to the $129-\mathrm{keV}$ quantum, when the data are corrected to time zero. The conclusions obtained from these data accord with the results reported in ref. 2 . 


\section{References}

1. S. V. Nablo, N. W. Johns, A. Artna, and R. H. Goodman, Can. J. Phys. 36 (1958) 1409.

2. 2. Plagner, L. Maly, N. Eissa, A. Benedek, Czech. J. Phys. B13 (1963) 23.

3. Nuclear Data Sheets, compiled by K. Way, et al: (Printing and Publishing Office, National Academy of Sciences - National Research Council, Washington, D. C., U.S.A. 


\section{Caption}

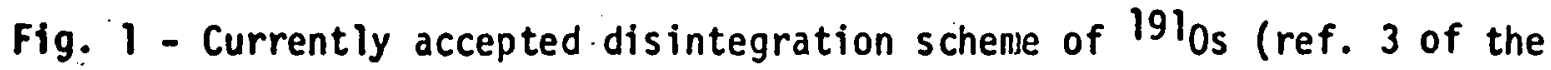
text). Spectrum of harder gamma rays of ${ }^{191} 0$ s at left. Decay of full energy peaks shown at right. All energies in keV. Results of measurements presently reported require removal of broken lines in the disintegration scheme. 
$\mathrm{Os}^{191}$

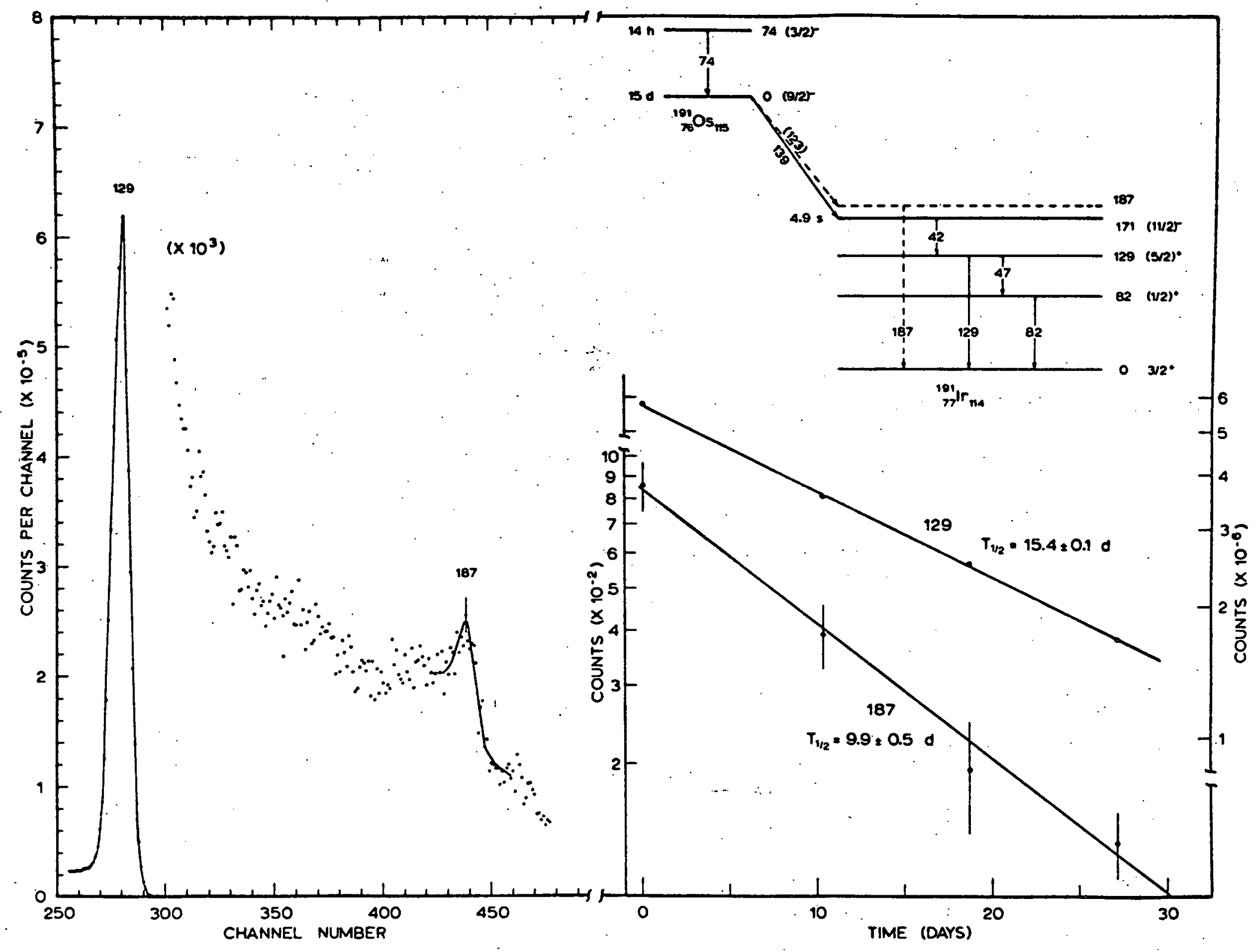

Fig. I 
IV. Nuclear Energy States of Eu ${ }^{155}$. 


\section{Abstract}

Isotopically concentrated ${ }^{154} \mathrm{Sm}$ has been irradiated in a research reactor to produce ${ }^{155} \mathrm{Sm}$ which decays by beta emission to ${ }^{155} \mathrm{Eu}$. Twentynine gamma rays, observed in Ge(Li) detectors, have been ordered in a nuclear structure diagram which contains levels having the following excitation energies in keV, spins, and parities: $0\left(\frac{5}{2}+\right), 79\left(\frac{7}{2}+\right), 105\left(\frac{5}{2}-\right)$, $168\left(\frac{7}{2}-\right), 246\left(\frac{3}{2}+\right), 307\left(\frac{5}{2}+\right), 614\left(\frac{7}{2}\right), 768\left(\frac{1}{2}+\right), 782\left(\frac{3}{2}+\right), 876\left(\frac{5}{2}+\right), 1102\left(\frac{3}{2}-\right)$, $1264\left(\frac{1}{2}-, \frac{1}{2}+, \frac{3}{2}+\right)$, and $1302\left(\frac{1}{2}, \frac{1}{2}+, \frac{3}{2}+\right)$. These nuclear states of ${ }^{155} \mathrm{Eu}$ have been assigned Nilsson numbers, or rotational properties. 


\section{Introduction}

The radiations of the 22 minute ${ }^{1)} 155 \mathrm{Sm}$ have been studied in the course of several recent investigations ${ }^{2-7)}$. Kracik et al. ${ }^{2)}$, employing magnetic spectrograph and scintillation spectrometry, reported the presence of thirteen gamma transitions which were interpreted to correspond to de-excitation of seven excited states in ${ }^{155} \mathrm{Eu}$, the residual nucleus. Also combining magnetic spectrograph and scintillation spectrometry. Funke et al. ${ }^{3)}$ reported seven beta spectra and twenty-five gamma transitions to be associated with the disintegration of ${ }^{155} \mathrm{Sm}$. These radiations were considered to indicate the presence of nine excited states in the nucleus of ${ }^{155} \mathrm{Eu}$. Agin et al. ${ }^{4)}$ observed twenty-two gamma rays from ${ }^{155} \mathrm{Sm}$ in a detector of $\mathrm{Ge}(\mathrm{Li})$, and commented specifically upon the presence of four excited states in ${ }^{155} \mathrm{Eu}$. In continued study of ${ }^{155} \mathrm{Sm}$, Funke et al. ${ }^{5)}$ detected thirty-four gamma transitions and located ten excited nuclear energy states in ${ }^{155} \mathrm{Eu}$. $\mathrm{Re}-$ investigation by Potnis et al. ${ }^{6)}$, again using $\mathrm{Ge}(\mathrm{Li})$ yielded evidence of the presence of twenty-eight gamma transitions in ${ }^{155} \mathrm{Eu}$. Sujkowski and Ungrin $^{7)}$ have reported thirty-six gamma rays to be emitted in the decay of ${ }^{155} \mathrm{Sm}$, employing $\mathrm{Ge}(\mathrm{Li})$ and $\mathrm{Si}(\mathrm{Li})$ spectrometry. The presently reported data may be regarded as resulting from an extension of the measurements of ref. ${ }^{6)}$.

\section{The Measurements}

To obtain sources of ${ }^{155} \mathrm{Sm}$, quantities of ${ }^{154} \mathrm{Sm}_{2} \mathrm{O}_{3}$ (isotopic concentration 99.26 percent) were successively exposed in amounts of $5 \mathrm{mg}$ each for periods of ten minutes, in the KSU Triga Mark II reactor. Gamma ray spectra of single counts were observed in a $\mathrm{Ge}(\mathrm{Li})$ detector of depletion layer inickness $4.2 \mathrm{~mm}$. The relative intensities of the gamma rays were obtained from the areas under the observed full energy peaks, after corrections were 
introduced to take into account preabsorbing materials before the detector, efficiency of the detector, and full energy peak-to-total ratio, as functions of garima ray energy.

The spectrum of the softer gamma rays of ${ }^{155} \mathrm{Sm}$ is shown in fig. 1. The spectrum of the harder gamma rays is presented in fig. 2. These data are ordered according to increasing quantum energy in table 1 , along with.calculated relative intensities. In table 1 are also given for comparison the energies and relative intensities of the gamma rays of ${ }^{155} \mathrm{Sm}$ as reported in ref. ${ }^{5)}$.

Two Ge(Li) detectors were placed in coincidence, and coincidences were measured between the $141 \mathrm{keV}$ gamma ray and some of the softer gamma rays of the spectrum. These data are shown in fig. 3. From this figure it is apparent that the $141 \mathrm{keV}$ gamma ray is coincident with quanta at 105, 79 ; and $63 \mathrm{keV}$, and with the $\mathrm{K}$-shell X-rays of europium. To obtain these results, the gating pulse from a slow-fast coincidence circuit was provided by the $141 \mathrm{keV}$ gamma, and the gamma ray spectrum coincident with it was displayed upon a multichannel analyzer. For the purpose of obtaining a necessary correction, a gating pulse was also taken from the region of energy just above $141 \mathrm{keV}$ to observe any coincidences between the gamma rays of fig. 3 and the compton distributions of gamma rays of high energy. These coincidences, as well as chance coincidences, were accumulated simultaneousiy with the total of coincidences of every variety, and subsequently subtracted from the total to give the genuine coincidences of fig. 3 . The full energy peak at $79 \mathrm{keV}$ is unduly intense because of the presence of backscattered radiation of the $105 \mathrm{keV}$ quanta.

Attempts to observe coincidence spectra generated by gating pulses of gamma rays at energies greater than $141 \mathrm{keV}$ failed because of the poor detection efficiency of the coincident $\mathrm{Ge}(\mathrm{L} \mathrm{i})$ detectors (depletion layer 
thicknesses $4.2 \mathrm{~mm}$ and $5 \mathrm{~mm}$ respectively), and because of the fact that the hard gamma rays of ${ }^{155} \mathrm{Sm}$ are few in number, ninety-three percent of the beta disintegrations feeding the $105 \mathrm{keV}$ level ${ }^{5)}$ of ${ }^{155} \mathrm{Eu}$.

\section{Discussion}

The data of table 1 show five gamma rays to have been reported in ref. 5 ) which were not detected by the techniques and methods of the present investigation. Evidence for the gamma rays at 135,860, and $1050 \mathrm{keV}$ had been earlier obtained with application of coincident scintillation spectrometers ${ }^{3)}$, and : the presence of the $280 \mathrm{keV}$ gamma ray was observed ${ }^{5)}$ in a single detector of $\mathrm{Ge}(\mathrm{Li})$. Since the results of table 1 also indicate that in the course of. the present study, gamma rays of comparable or smaller intensity than the four above cited were indeed satisfactorily observed, no obvious explanation for the differing observations is apparent. Whether the presence of these four gamma rays ${ }^{3,5}$ ) might be related to contaminating ${ }^{5)} 1.52$ Eu is not certain. The presently unobserved fifth gamma ray is, of course, the one of energy $26 \mathrm{keV}$. Its intensity at the surface of the quantum sensitive $\mathrm{Ge}(\mathrm{Li})$ was too heavily reduced by preabsorbing materials such as lucite, aluminum and germanium. The lucite shield, thickness $0.64 \mathrm{~cm}$, was introduced to stop hard beta rays from the source of ${ }^{155} \mathrm{Sm}$, and the $\mathrm{Ge}(\mathrm{Li})$ detector was housed in an aluminum cup of wall thickness $0.0384 \mathrm{~cm}$. The "dead layer" of germanium, before the sensitive volume of the detector, had a thickness of $0.03 \mathrm{~cm}$.

The data of figs. 1-3 are summarized in fig. 4 where the nuclear level structure of ${ }^{155} \mathrm{Eu}$ is given. The measured ${ }^{8}$ ). spin values of the ground states of ${ }^{151} \mathrm{Eu}$ and ${ }^{153} \mathrm{Eu}$ are each $\frac{5}{2}$. By analogy, the spin of the ground state of ${ }^{155}$ Eu can also be considered to be $\frac{5}{2}$. Gamma-gamma spatial correiation studies ${ }^{9}$ ) provide for the ground state and the excited states at 105 and $24 \ddot{\mathrm{f}} \mathrm{keV}$ a spin sequence of $\frac{5}{2}, \frac{5}{2}, \frac{3}{2}$. Internal conversion studies 2,10$)$ suggest the 105, 141, and $246 \mathrm{keV}$ transitions to $E 7+M 2, E]+M 2$, and $M I+E 2$ in character. Both the 
correlation experiments and these measurements of the conversion coefficients are consistent with spin-parity assignments of $\frac{3}{2}, \frac{5}{2}$, and $\frac{5}{2}+$ for the $246 \mathrm{keV}$ and $105 \mathrm{keV}$.excited states, and the ground state. On the Nilsson diagram ${ }^{11}$ ), the spacing in energy of the ground state and the 105 and $246 \mathrm{keV}$ levels corresponds to a value of the deformation parameter of ${ }^{155} \mathrm{Eu}$ of about 0.2 , which in turn indicates $\mathrm{Nilss}$ on quantum numbers of $\frac{5}{2}+[413]$ for the ground state of ${ }^{155} \mathrm{Eu}$, and $\frac{5}{2}-[532]$ and $\frac{3}{2}+[411]$ as Nilsson quantum numbers for the states at 105 and $246 \mathrm{keV}$ respectively. Additional considerations of energy spacinas of the nuclear states result in the choice of $\frac{7}{2}-[523], \frac{7}{2}+[411]$, and $\frac{3}{2}-[541]$ for Nilsson numbers of the states at 614,768 , and $1102 \mathrm{keV}$. Similarly, Nilsson numbers of $\frac{1}{2}+[420], \frac{3}{2}+[122]$, or $\frac{1}{2}-[550]$ could be assigned to either of the energy states at 1264 and $1302 \mathrm{keV}$. The state at $79 \mathrm{keV}$ is interpreted as being the second member of a rotational band ${ }^{12)}$ based upon the ground state. The $168 \mathrm{keV}$ state is interpreted as occupying an analagous position relative to the $105 \mathrm{keV}$ Nilsson state. The $307 \mathrm{keV}$ state is considered to be the second member of a rotational band founded upon the $246 \mathrm{keV}$ single particle state, and the 782 and $876 \mathrm{keV}$ states are assumed to be the second and third members of a rotational band commencing with the $768 \mathrm{keV}$ state of spin-parity designation $\frac{1}{2}+$. The energy spacings of the states of this particular rotational band yield a value of -0.50 for the decoupling parameter ${ }^{12}$. The arguments of the paragraphs immediately preceding provide the spinparity assignments of the nuclear states presented in fig. 4.

\section{Acknowledgments}

The writers wish to express appreciation for discussion with Dr. P. M. Rinard concerning theoretical aspects of this problem and for the cooperation of Dr. Walter Meyer in carrying out irradiations. 
Energies and relative intensities of the gamma rays of ${ }^{155} \mathrm{Sm}$. Energies are in keV. Relative intensities are included between parenthetical marks.

\begin{tabular}{|c|c|}
\hline ref. ${ }^{5)}$ & Present results \\
\hline $26(11 \pm 5)$ & $\ldots$ \\
\hline $62(4.5 \pm 1.5)$ & $63(6.6 \pm 0.6)$ \\
\hline $79(4.5 \pm 1.5)$ & $79(\leq 0.5)$ \\
\hline $105(2000 \pm 200)$ & $.105(2270 \pm 40)$ \\
\hline $135 \ldots$ & ----- \\
\hline $141(45 \pm 5)$ & $141(54 \pm 2)$ \\
\hline $168(1.8 \pm 0.3)$ & $168(1.7 \pm 0.3)$ \\
\hline $203(4.0 \pm 1.5)$ & $203(1.0 \pm 0.2)$ \\
\hline $229(1.2 \pm 0.2)$ & $229(1.3 \pm 0.1)$ \\
\hline $246(100)$ & $246(100)$ \\
\hline $280(0.4 \pm 0.1)$ & $=-\cdots$ \\
\hline $307(0.4 \pm 0.1)$ & $307(0.20 \pm 0.05)$ \\
\hline $429(0.4 \pm 0.1)$ & $429(0.36 \pm 0.04)$ \\
\hline $462(1.8 \pm 0.2)$ & $462(2.03 \pm 0.05)$ \\
\hline $509(0.5 \pm 0.1)$ & $509(0.30 \pm 0.04)$ \\
\hline $522(4.4 \pm 0.3)$ & $522(4.33 \pm 0.06)$ \\
\hline $570(0.6 \pm 0.1)$ & $570(0.62 \pm 0.04)$ \\
\hline $602(0.4 \pm 0.1)$ & $602(0.39 \pm 0.04)$ \\
\hline $630(0.6 \pm 0.1)$ & $630(0.52 \pm 0.04)$ \\
\hline
\end{tabular}




\section{Table I ( continued)}

$\begin{array}{ll}647(0.20 \pm 0.7) & 650(0.30 \pm 0.04) \\ 663(1.9 \pm 0.2) & 663(1.81 \pm 0.05) \\ 676(0.18 \pm 0.07) & 677(0.20 \pm 0.05) \\ 710(0.23 \pm 0.08) & 711(0.20 \pm 0.05) \\ 768(0.22 \pm 0.08) & 768(0.16 \pm 0.05) \\ 860(0.1) & \vdots-\cdots \\ 931(0.18 \pm 0.03) & 931(0.37 \pm 0.06) \\ 996(0.4 \pm 0.2) & 997(0.26 \pm 0.05) \\ 1004(0.5 \pm 0.2) & 1000(0.56 \pm 0.06) \\ 1050(0.2) & -\cdots \\ 1158(0.33 \pm 0.06) & 1160(0.30 \pm 0.04) \\ 1197(0.16 \pm 0.04) & 1200(0.12 \pm 0.03) \\ 1223(0.7 \pm 0.1) & 1225(0.62 \pm 0.03) \\ 1262(0.14 \pm 0.05) & 1264(0.08 \pm 0.02) \\ 1302(2.6 \pm 0.3) & 1302(2.11 \pm 0.06)\end{array}$




\section{References}

1. M. L. Pool and L. L. Quill, Phys. Rev. 53 (1938). 437

2. B. Kracik, Z. Miligui, V. Brabec, M. Vejs, A. Mastalka, and T. Kucarova, Czech. J. Phys. B13 (1963) 79

3. L. Funke, H. Graber, K. H. Kaun, H. Sodan, and L. Werner, Nuclear Physics 70 (1965) 335

4. G. P. Agin, L. D. Ellsworth, C. E. Mandeville, E. B. Nieschmidt, and V. R. Potnis; Bull. Am. Phys. Soc. Series II, 11 (1966) 408

5. L. Funke, H. Graber, K. H. Kaun, H. Sodan, and J. Frana, Nuclear Physics 88 (1966) 641

6. V. R. Potnis, G. P. Agin, and C. E. Mandeville, Bull. Am. Phys. Soc. Series 11, 12 (1967) 579

7. Z. Sujkowski and J. Ungrin, Bull. Am. Phys. Soc. Series II, 12 (1967) 714

8. J. M. Baker and F. I. B. Williams, Proc. Roy. Soc. (London) 267A (1962) 283

9. R. E. Sund, R. G. Arns, and M. L. Wiedenbeck, Phys. Rev. 118 (1960) 776

10. L. C. Schmid and S. B. Burson, Phys. Rev. 115 (1959) 447

11. B. R. Mottelson and S. G. Nilsson, K. Danske Vidensk. Selsk. mat.-fys. Skr. 1 (1959) No. 8

12. A. Bohr and B. R. Mottelson, K. Danske Vidensk. Selsk. mat. -fys. Medd. 27 (1953) No. 16 


\section{Captions}

Fig. 1 - Spectrum of the softer gamma rays of ${ }^{155} \mathrm{Sm}$. Energies in keV.

Fig. 2 - Spectrum of the harder gamma rays of ${ }^{155} \mathrm{Sm}$. Energies in keV. Absorbers intervening between source and detector were of lead, thickness $1.9 \mathrm{~mm}$, and of cadmi um, thickness $1.2 \mathrm{~mm}$.

Fig. 3 - Spectrum of the gamma rays of ${ }^{155}$ Sm coincident with quanta of energy $141 \mathrm{keV}$. Energies are in keV. These data were obtained when two $G e(L i)$ detectors were placed in coincidence.

Fig. 4 - Nuclear structure diagram for ${ }^{155} \mathrm{Eu}$. The nuclear states were ordered in energy according to the measurements of the present and certain coincidence experiments of ref. ${ }^{3)}$. 


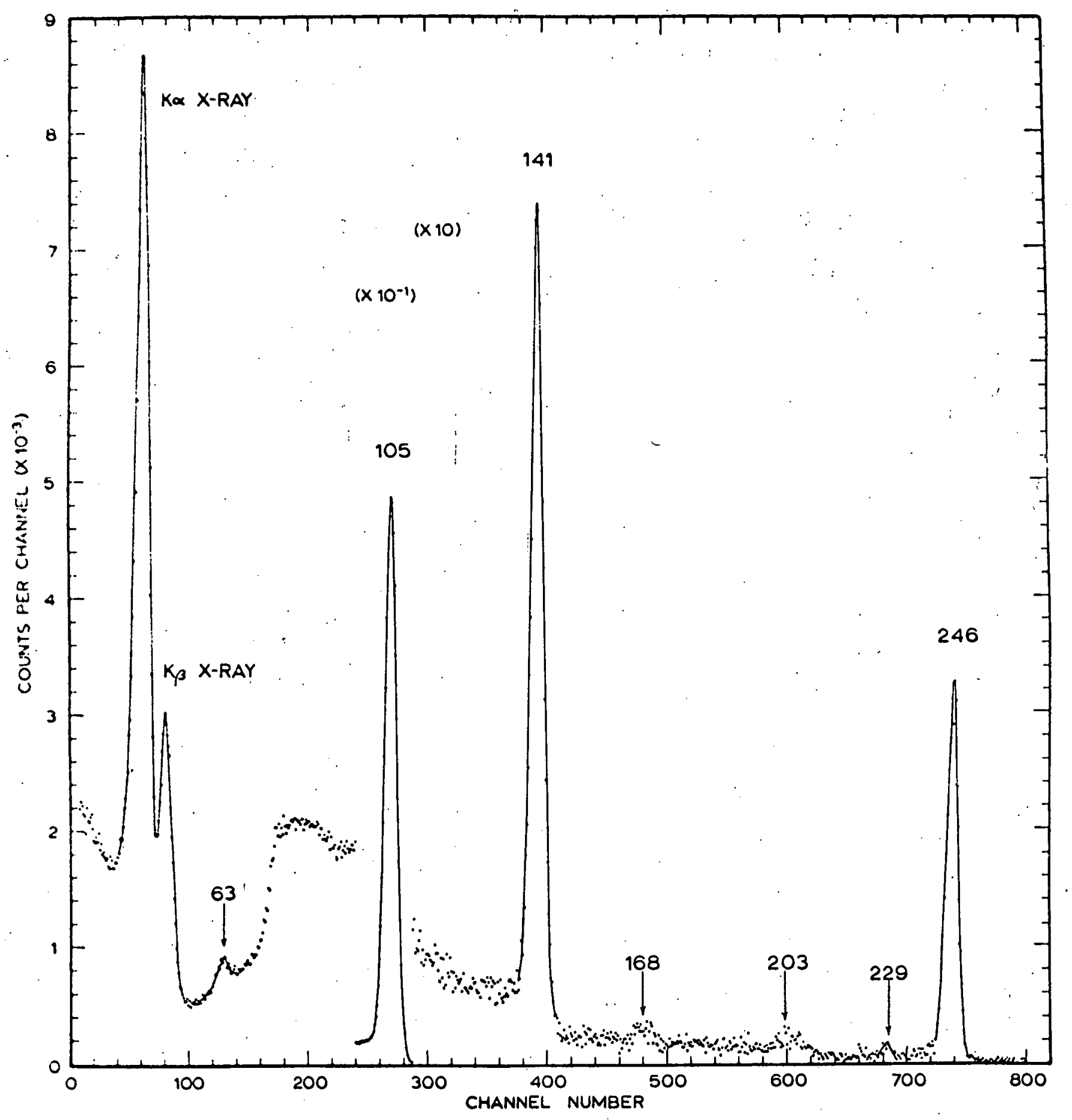

F18: 1 


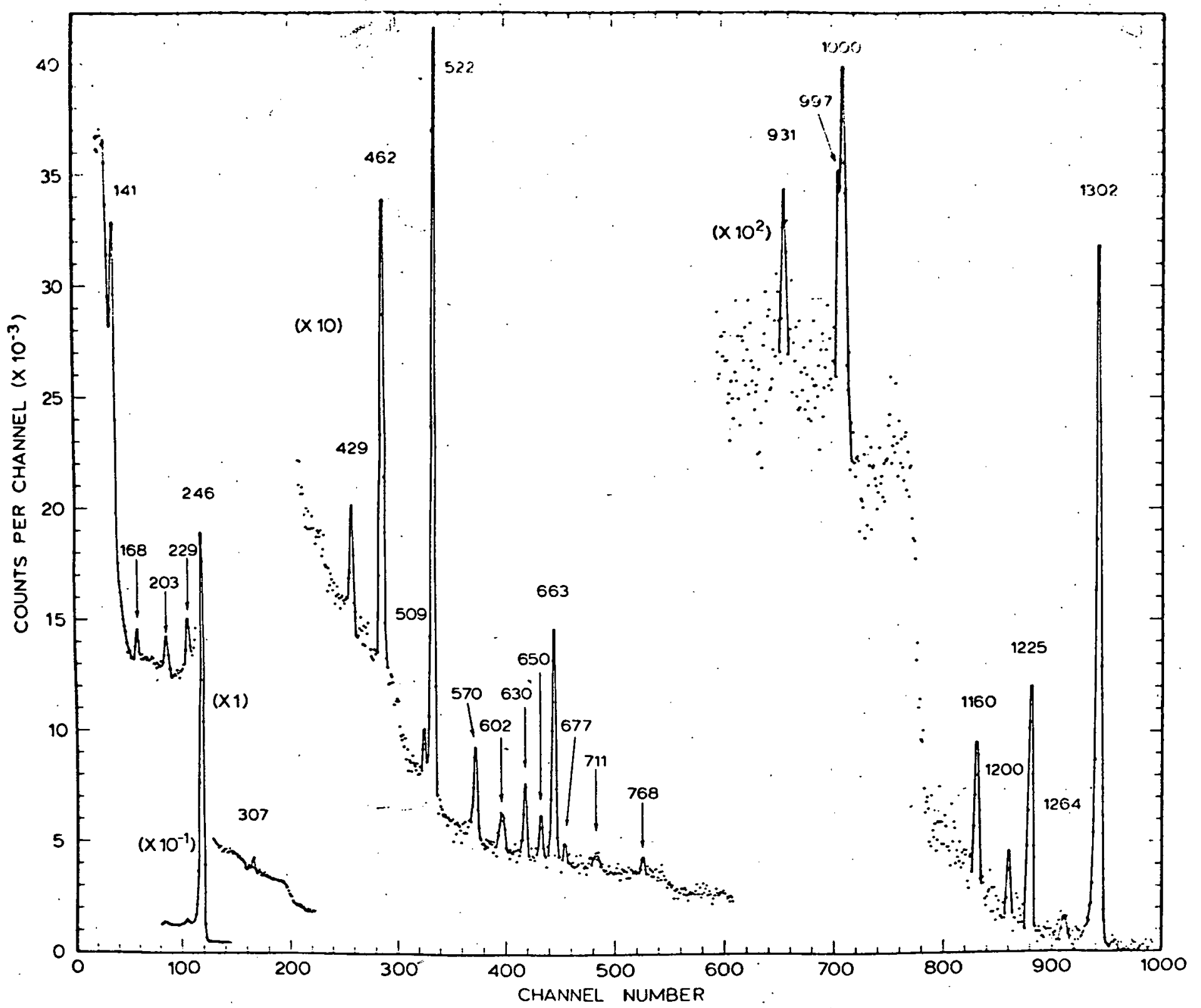

Fig. 2 


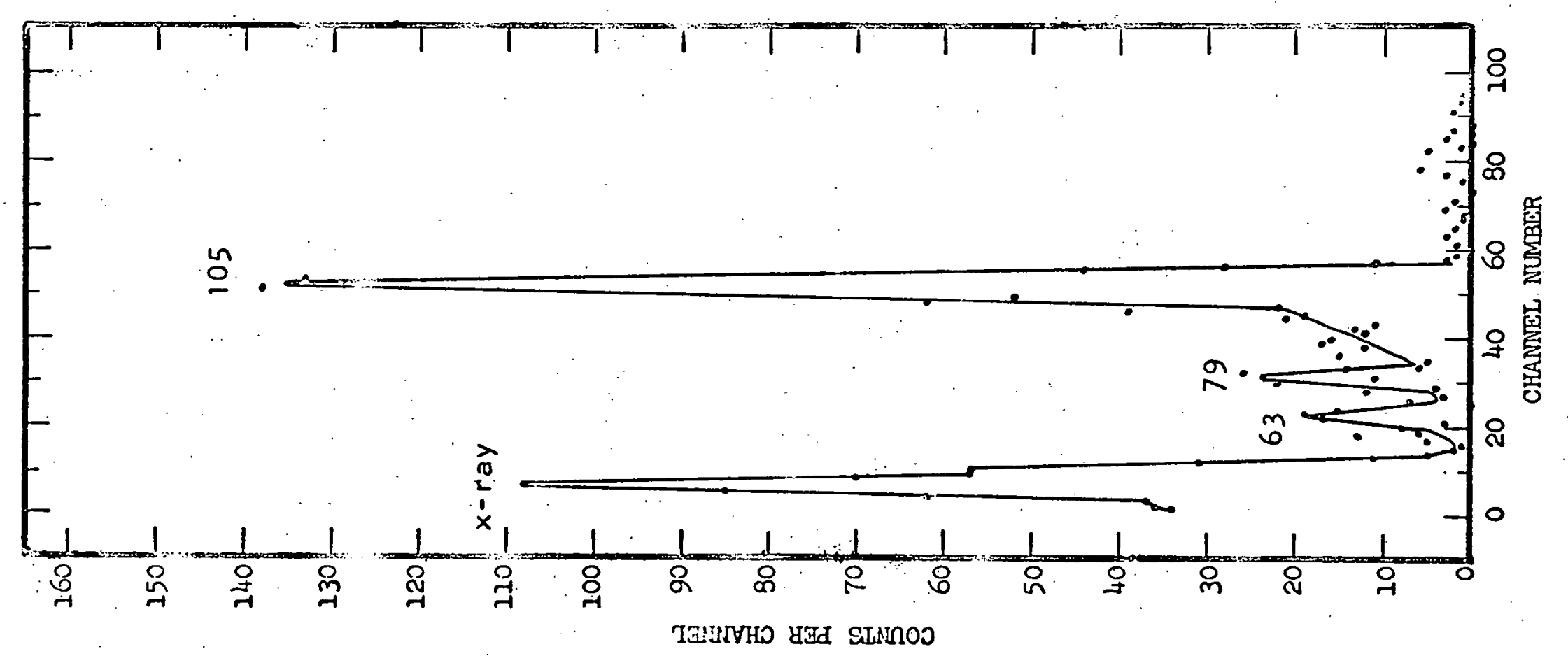




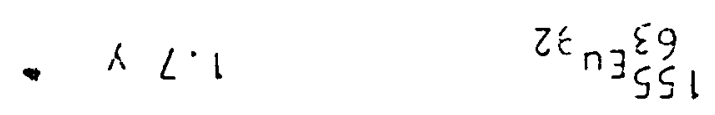

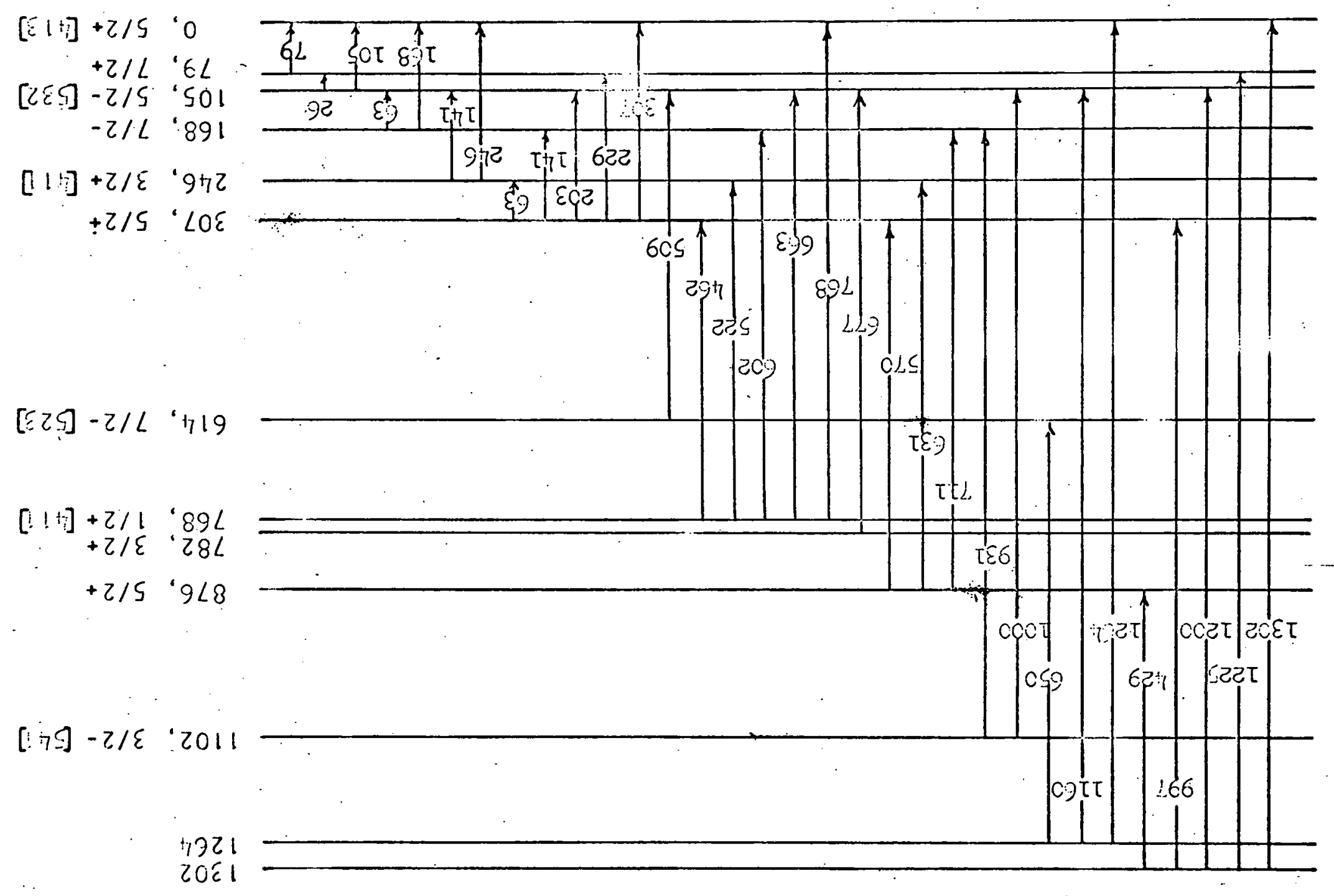


V. Gamma Rays Emitted in Disintegration of $\underline{I r}^{192}$ and Ir $^{194}$. see huclew Ghysion A95 (1967) $623-682$ 
VI. Additional Studies

$-32$ 
At the time of preparation of this report, many additional experiments are in progress. Under study are the radiations of the following elements.

$$
\begin{gathered}
\mathrm{Zr}^{97}-\mathrm{Nb}^{97} \\
\mathrm{Ba}^{139} \\
\mathrm{Ce}^{143} \\
\mathrm{Er}{ }^{171} \\
W^{187} \\
\mathrm{Pt}^{199}
\end{gathered}
$$

Among these disintegrating elements, many previously unreported gamma transitions have been discovered. Certain transitions earlier reported by others have not been observed. 
VII. Personnel

$-34-$ 